\title{
Microbicidal/Cytotoxic Proteins of Neutrophils Are Deficient in Two Disorders: Chediak-Higashi Syndrome and "Specific" Granule Deficiency
}

\author{
Tomas Ganz,"* Julia A. Metcalf," John I. Gallin," Laurence A. Boxer," and Robert I. Lehrer* \\ *Will Rogers Institute Pulmonary Research Laboratory and ${ }^{\ddagger}$ Department of Medicine, University of California, Los Angeles, \\ California 90024; 'Bacterial Diseases Section, Laboratory of Clinical Investigation, National Institute of Allergy \\ and Infectious Diseases, National Institutes of Health, Bethesda, Maryland 20294; and "Department of Pediatrics, \\ Mott Children's Hospital, University of Michigan, Ann Arbor, Michigan 48109
}

\begin{abstract}
Although several genetic defects are known to impair oxidative microbicidal/cytotoxic mechanisms in human PMN, no deficiencies of PMN granule components that mediate oxygen-independent microbicidal activity have yet been reported. We analyzed PMN from patients with various granulocyte disorders for their content of two azurophil granule constituents, defensins and cathepsin G, that exert microbicidal/cytotoxic activity in vitro, and one component, elastase, that has ancillary microbicidal/cytotoxic activity. PMN from two (of two) patients with specific granule deficiency (SGD) displayed an almost complete deficiency of defensins, which in normal cells constitute $>30 \%$ of the protein content of azurophil granules. The SGD PMN contained normal or mildly decreased amounts of cathepsin $G$ and elastase. Conversely, the PMN of three (of three) patients with Chediak-Higashi syndrome (CHS) substantially lacked cathepsin $\mathrm{G}$ and elastase, but their defensin content was normal or mildly decreased. Both CHS and SGD patients suffer from frequent and severe bacterial infections, and CHS patients frequently develop an atypical lymphoproliferative syndrome. The profound deficiency of PMN components with microbicidal/cytotoxic activity in SGD and CHS may contribute to the clinical manifestations of these disorders.
\end{abstract}

\section{Introduction}

Neutrophils are thought to kill their targets using two distinct classes of effector substances: reactive oxygen intermediates $(\mathrm{ROI})^{1}$ and microbicidal/cytotoxic proteins. Whereas myeloperoxidase deficiency and chronic granulomatous disease

Address reprint requests to Dr. Tomas Ganz, CHS 37-131, Department of Medicine, University of California, Los Angeles, California, 90024-1736.

This work was presented in part at the Annual Meeting of the American Federation for Clinical Research, 1-4 May, 1987. (1987. Clin. Res. 35:424a.)

Received for publication 4 August 1987 and in revised form 21 March 1988.

1. Abbreviations used in this paper: AU-PAGE, acid-urea PAGE; BCA, bicinchoninic acid; CHS, Chediak-Higashi syndrome; CGD, chronic granulomatous disease; ROI, reactive oxygen intermediates; SGD, specific granule deficiency.

J. Clin. Invest.

(c) The American Society for Clinical Investigation, Inc.

0021-9738/88/08/0552/05 $\$ 2.00$

Volume 82, August 1988, 552-556
(CGD) are well-studied examples of deficient ROI production by PMN (reviewed in references 1 and 2), analogous defects of microbicidal/cytotoxic proteins have not been described previously in human PMN. We have discovered and now report that in two conditions, PMN are deficient in certain microbicidal and cytotoxic proteins.

\section{Methods}

Subjects. Blood samples were obtained from normal volunteers ( $n$ $=17$ ), patients with known defects of ROI production (CGD, $n=20$; myeloperoxidase deficiency, $n=1$ ), and patients with other PMN defects: hyperimmunoglobulinemia E with recurrent infection (Job's syndrome), $n=5$; iC $3 \mathrm{~b}$ receptor deficiency, $n=1$; Chediak-Higashi syndrome (CHS), $n=3$; specific granule deficiency (SGD), $n=2$; and frequent bacterial infections without a specific diagnosis, $n=1$. The clinical and laboratory features of both SGD patients (cases 2 and 5 in reference 3) and two of the three CHS patients (cases 3 and 4 of reference 4 ) have been reported previously $(3,4)$.

$P M N$. PMN were purified by dextran sedimentation and centrifugation through a Hypaque-Ficoll step gradient (5). Granule-enriched PMN fractions (granules) were prepared by brief sonication of PMN in $0.34 \mathrm{M}$ sucrose, $\mathrm{pH} 7.4$, removal of nuclei and cell fragments by centrifugation at $200 \mathrm{~g}$ for $10 \mathrm{~min}$, and recovery of a granule-enriched sediment by ultracentrifugation (Airfuge; Beckman Instruments, Fullerton, CA; 20 psi for $5 \mathrm{~min}$ ). PMN and granules were stored frozen at $-70^{\circ} \mathrm{C}$ except during shipment on dry ice.

Screening by $P A G E$. Aliquots of $5 \times 10^{6}$ cells of their granules were solubilized by brief sonication at $4^{\circ} \mathrm{C}$ in $0.5 \mathrm{ml} 5 \%$ acetic acid. After additional incubation at $4^{\circ} \mathrm{C}$ for $2 \mathrm{~h}$, the lysate was cleared by centrifugation at $12,000 \mathrm{~g}$ for $10 \mathrm{~min}$ and lyophilized aliquots were analyzed by electrophoresis on $12.5 \%$ acid-urea polyacrylamide gels (AU-PAGE) and $10-30 \%$ gradient SDS-PAGE. The gels were stained with Coomassie Blue and examined for missing or abnormal protein bands by observers who were blinded to the patients' identity or diagnosis. The missing proteins were tentatively identified by comparison of their migration to that of individually purified granule proteins.

Western blots. To detect defensins or elastase, AU-PAGE of PMN extracts were electroblotted to nitrocellulose membranes in $0.7 \%$ acetic acid, blots were probed with 1:500 dilutions of sheep anti-elastase IgG (Miles Scientific Division, Miles Laboratories, Inc., Naperville, IL) or rabbit anti-defensins IgG (6), and 1:2,000 dilutions of appropriate second antibody IgG coupled to horseradish peroxidase (Cappel Laboratories, Cochranville, PA). The blots were developed in 1-chloronaphthol as described by the manufacturer (Bio-Rad Laboratories, Richmond, CA). Purified neutrophil elastase and cathepsin G (Elastin Products, St. Louis, MO), or defensins (6) were used as standards.

Alternatively, for the detection of cathepsin G, PMN were extracted by brief sonication in $0.1 \mathrm{M}$ sodium acetate $/ 0.2 \%$ cetyltrimethylammonium bromide. The extract was cleared by centrifugation and subjected to electrophoresis on an acid ( $\mathrm{pH} 4.3$ ) $12.5 \%$ polyacrylamide slab gel prepared by a minor modification of the method of Reisfeld et al. (7). The bisacrylamide content in solution $C$ was increased to $2.5 \% \mathrm{wt} / \mathrm{vol}$. The running gel consisted of solutions $\mathrm{A}, \mathrm{C}, \mathrm{E}$, 
and water in the ratio 3:5:3:13. The stacking layer was prepared from solutions B, D, E, and water in the volume ratio 1:3:1:3. All solutions are as described in reference 7 . Both layers were photopolymerized. The gel was electroblotted onto nitrocellulose overnight in tray buffer (7) diluted 1:1 with water. The blot was probed with 1:100 dilution of sheep anti-cathepsin G antibody (Miles Scientific), followed by 1:500 dilution of rabbit anti-goat IgG antibody coupled to horseradish peroxidase (Cappel Laboratories), then developed as described before.

Elastase and cathepsin $G$ assays. PMN were sonicated in $0.1 \mathrm{M}$ sodium acetate $/ 0.2 \%$ cetyltrimethylammonium bromide, $\mathrm{pH} 4.0$, at $4^{\circ} \mathrm{C}$ at a concentration of $1 \times 10^{7} \mathrm{PMN} / \mathrm{ml}$. Elastase activity at $37^{\circ} \mathrm{C}$ was measured from the slope of the absorbance at $410 \mathrm{~nm}$ of a mixture containing $0.010 \mathrm{ml}$ of PMN sonicate and $0.99 \mathrm{ml}$ of the specific substrate $0.2 \mathrm{mM}$ methoxysuccinyl-alanyl-alanyl-prolyl-valine-p-nitroanilide (Sigma Chemical Co., St. Louis, MO) in $0.2 \mathrm{M}$ Tris-HCl pH 8.0/10\% DMSO (8). Cathepsin G activity was determined similarly by adding $0.040 \mathrm{ml}$ of PMN lysate to $0.96 \mathrm{ml}$ of $1.1 \mathrm{mM}$ succinyl-alanylalanyl-prolyl-phenylalanine-p-nitroanilide (Sigma Chemical Co.) in the same buffer (9).

Defensin assays. Defensin concentrations were determined by a competitive enzyme immunoassay described previously (9).

Protein assays. The amounts of soluble protein in PMN lysates were determined using a modification of the bicinchoninic acid (BCA) protein assay (10). The standard BCA protein reagent was prepared according to the manufacturer's instructions (Pierce Chemical Co., Rockford, IL). The assay was performed in triplicate in 96-well microtiter plates by adding $200 \mu \mathrm{l}$ of BCA reagent to $5 \mu \mathrm{l}$ of PMN lysate or hen egg lysozyme standard (Sigma Chemical Co.), and incubating at $60^{\circ} \mathrm{C}$ for $30 \mathrm{~min}$. The plates were read on an enzyme immunoassay reader at $540 \mathrm{~nm}$ and protein concentrations calculated by linear regression.

\section{Results}

AU-PAGE and SDS-PAGE profiles of whole PMN extracts and PMN granule extracts revealed qualitative abnormalities in three classes of patients: myeloperoxidase deficiency, SGD, and CHS. As expected, the characteristic myeloperoxidase bands were absent in the extracts of PMN from a patient with a deficiency of this enzyme, and the specific granule marker lactoferrin was absent from extracts of PMN of both patients with SGD. More remarkably, PMN from two of two patients with SGD also appeared to be markedly deficient in all three defensins whereas PMN of three of three patients with CHS appeared to lack neutrophil elastase. Representative examples of screening electrophoretograms are shown in Fig. 1. Compared with extracts of whole PMN, granule extracts yielded less complex patterns, making them particularly suitable as qualitative screening tools for the detection of granule defects. Others also noted (11) an apparent deficiency of all azurophil granule proteins in the granule-enriched fraction of CHS neutrophils $(G)$ which was thought to reflect the insufficient recovery of these morphologically abnormal granules by the conventional granule enrichment procedures. Accordingly, we used whole PMN extracts rather than granule extracts for the subsequent studies.

We quantified the immunoreactive defensin content, and elastase and cathepsin G enzymatic activities in whole PMN extracts (Fig. 2). PMN of the two SGD patients contained only 10 and $9 \%$, respectively, of the mean defensin content of normal PMN, and had the lowest defensin content of all 50 donors tested $(P<0.001)$. In both SGD patients, elastase ( 55 and $96 \%$ ) and cathepsin $G(32$ and $85 \%$ ) activities were relatively preserved, as was the acid-extractable protein content (67 and 104\%, see Table I). Conversely, the PMN of the three patients with CHS showed severely diminished elastase $(3,12$, and $12 \%)$ and cathepsin $G(3,11$, and $13 \%)$ activity, ranking the lowest of 40 donors tested for each enzyme $(P=0.0001)$, but their defensin content was relatively preserved $(36,47$, and $103 \%)$, as was their acid-extractable protein content $(90,90$, and $82 \%$, see Table I). The enzyme activity of mixtures of CHS and normal PMN extracts was additive for both elastase and cathepsin G (data not shown) indicating that the low elastase and cathepsin G activity of CHS PMN was not due to a protease inhibitor.

Western blots of PMN extracts from SGD patients, CHS patients, and normal controls (Figs. 3 and 4) confirmed these

\section{SGD CONTROLS CONTROLS CHS}

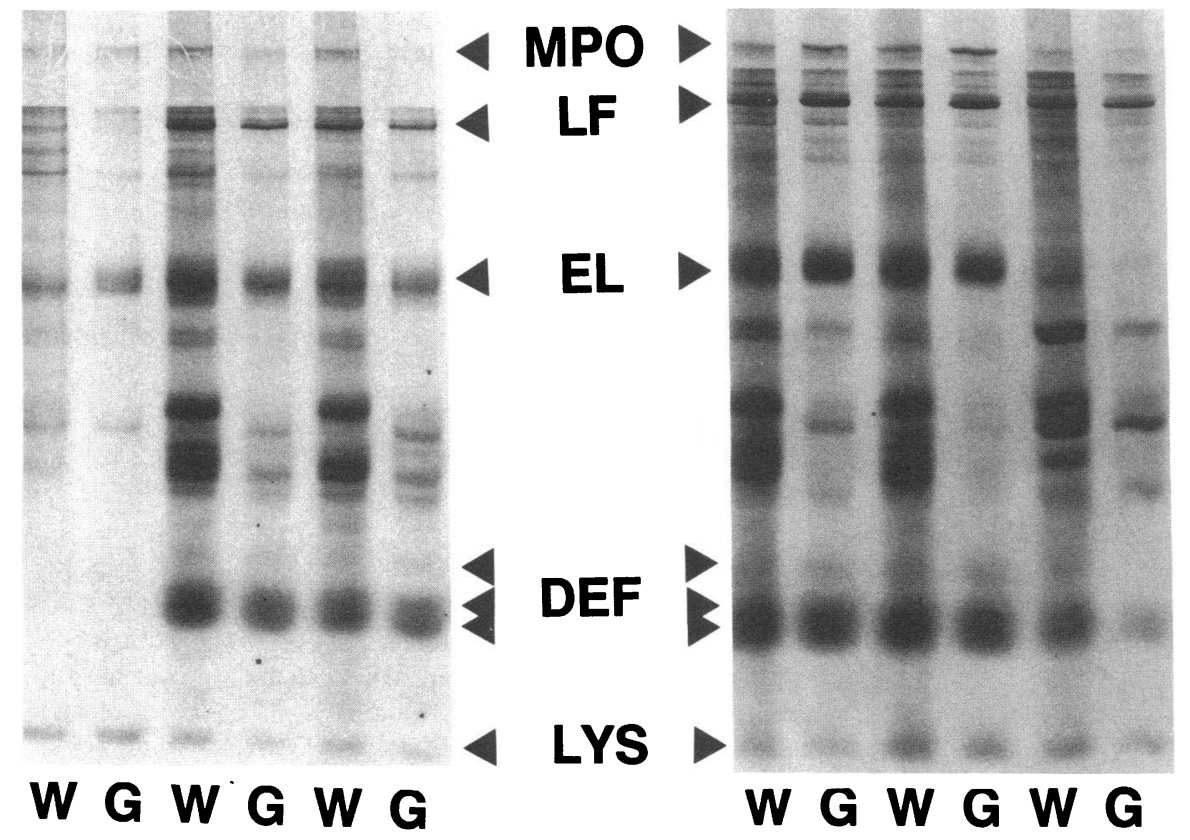

Figure 1. Representative screening electrophoretograms (AU-PAGE) of PMN extracts from normal controls and patients. Each subject's whole PMN extract (W) and granule extract $(G)$ are analyzed in adjacent lanes. Controls in this case include three patients with CGD and one normal subject. Purified major granule proteins migrate as indicated by arrows: MPO, myeloperoxidase; LF, lactoferrin; EL, elastase; DEF, the three human defensins, HNP-1,2, and 3; LYS, lysozyme. The extract of SGD neutrophils (SGD 1 in Table I) shows normal lysozyme and myeloperoxidase bands, a somewhat diminished elastase band, and missing lactoferrin and defensin bands. The extract of whole CHS neutrophils (W) shows normal lysozyme and lactoferrin bands, somewhat diminished myeloperoxidase and defensin bands, and absent elastase bands (sample CHS 1 in Table I). The paucity of all azurophil granule proteins in the conventionally granule-enriched fraction $(G)$ of CHS neutrophils was noted previously by West (11). 


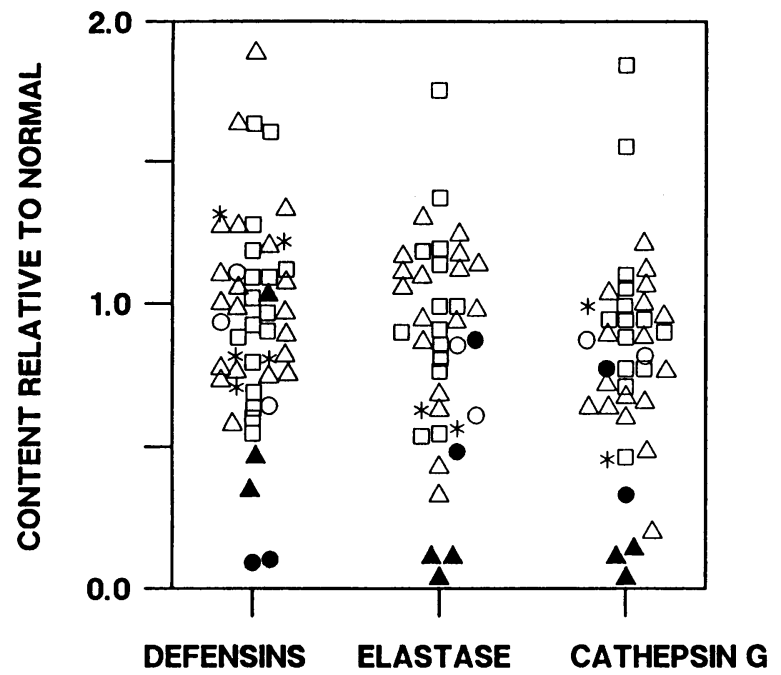

Figure 2. The content of defensins, elastase and cathepsin G in PMN of individual patients and normal controls. The measurements are expressed relative to the mean of normal controls for each protein. $\square$, normal; $\triangle$, CGD; ๑, SGD;, CHS; *, Jobs' syndrome; ০, other.

quantitative defects but, with one exception, detected no abnormally migrating immunoreactive elastase, cathepsin $\mathrm{G}$, or defensins. An additional protein band not present in any of the other patients or controls and cross-reactive with elastase was seen in PMN extracts of one of the SGD patients (case 2, reference 3 ). The properties of this abnormal protein are under investigation.

As a group, PMN of patients with CGD did not differ from normal controls (NL) in their content of defensins, elastase, or cathepsin G $(95 \%$ confidence interval for the difference of means, CGD-NL: elastase, -18 to $+20 \%$; cathepsin G, -32 to $+7 \%$; defensins, -17 to $+29 \%$ ). Although only a few could be tested, patients with hyperimmunoglobulinemia E-recurrent infection (Job's syndrome) did not manifest deficiencies of any of the three proteins studied (Fig. 2).

Table I. Protein Content of PMN Extracts

\begin{tabular}{lcc}
\hline \multicolumn{1}{c}{ Patient groups } & HOAc extract* & $\begin{array}{c}\text { NaOAc/CETAB } \\
\text { extract }^{*}\end{array}$ \\
\hline \multicolumn{3}{c}{$\mu g$} \\
Normal & $40 \pm 6(n=11)$ & $45 \pm 3(n=15)$ \\
CGD & $40 \pm 6(n=14)$ & $47 \pm 7(n=17)$ \\
Other PMN defects & $39 \pm 5(n=8)$ & $40 \pm 5(n=9)$ \\
Individual CHS and SGD patients & \\
SGD 1 & Not done & 31 \\
SGD 2 & 44 & 44 \\
CHS 1 & 38 & 38 \\
CHS 2 & 49 & 47 \\
CHS 3 & 34 & 35 \\
& & \\
\hline
\end{tabular}

* Protein content of $5 \%$ acetic acid extract per $10^{6}$ whole PMN (mean $\pm \mathrm{SD}, n=$ number of patients).

${ }^{\ddagger}$ Protein content of $0.1 \mathrm{M}$ sodium acetate/0.2\% CETAB extract per $10^{6}$ whole PMN (mean \pm SD, $n=$ number of patients).

\section{ELASTASE}

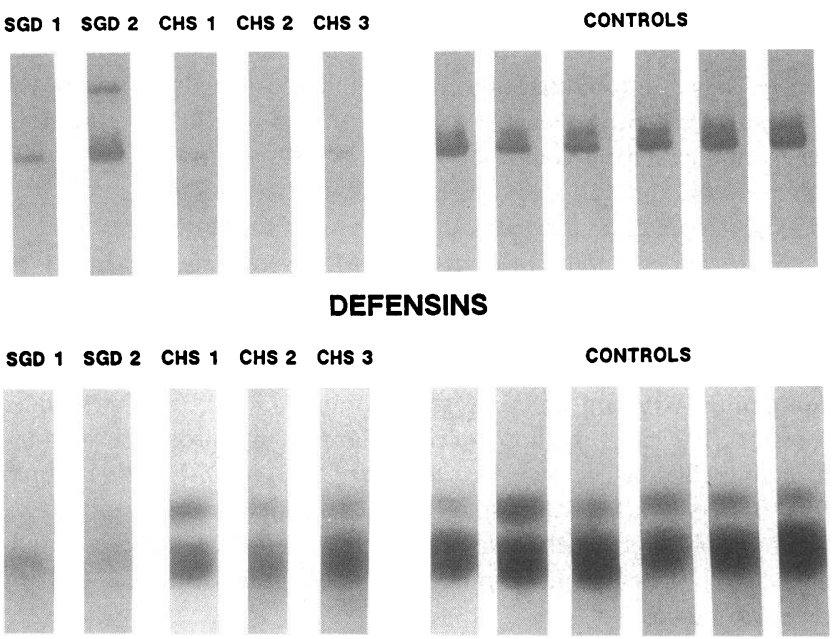

Figure 3. Western blots of CHS, SGD, and control whole PMN extracts. Top, reacted with anti-elastase antibody, bottom, anti-defensin antibody. The controls included normal controls $(n=3)$ and patients with CGD $(n=3)$. Each lane contains extract from $3 \times 10^{5}$ PMN (anti-elastase) or $1 \times 10^{5} \mathrm{PMN}$ (anti-defensins). The protein contents of CHS PMN extracts (35-49 $\mu \mathrm{g} / 10^{6}$ cell equivalents), SGD PMN extracts (31-44 $\mu \mathrm{g} / 10^{6}$ cell equivalents) and control PMN extracts $\left(28-50 \mu \mathrm{g} / 10^{6}\right.$ cell equivalents) were similar.

\section{Discussion}

CHS. Although our observations of cathepsin $\mathrm{G}$ and elastase deficiency in CHS patients are novel, they are in agreement with previous reports (12) of diminished neutral protease ac-

\section{CATHEPSIN G}

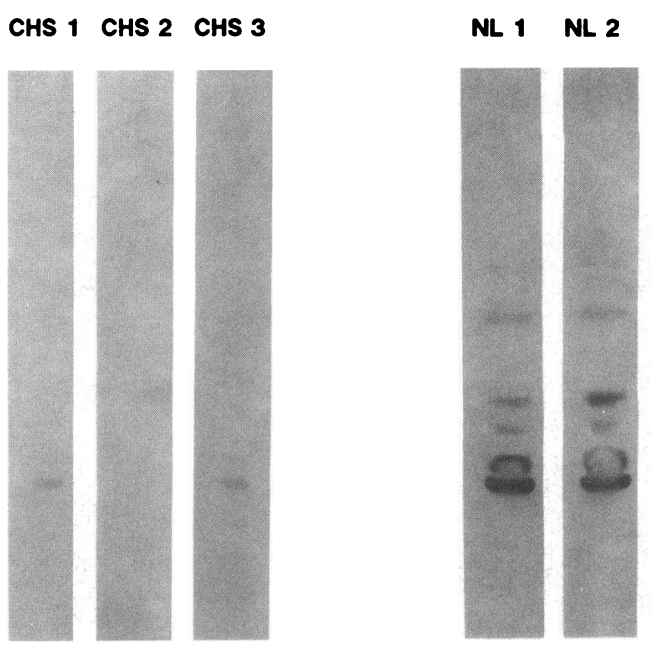

Figure 4. Western blots of CHS and normal PMN extracts probed with anti-cathepsin $G$ antibody. Each lane contains extract of 5 $\times 10^{5}$ whole PMN. The protein contents of CHS PMN extracts (35-49 $\mu \mathrm{g} / 10^{6}$ cell equivalents) were similar to the two concurrently processed normal PMN extracts ( 31 and $50 \mu \mathrm{g} / 10^{6}$ cell equivalents). The enzymatically active forms of cathepsin $G$ migrate in the two prominent cathodal bands (at the bottom of the strip) seen in lanes $N L I$ and $N L 2$. 
tivity in CHS PMN and in the PMN of beige mice (an animal model of CHS). More recent studies in beige mice, using specific enzymatic substrates, determined that both elastase and cathepsin $G$ enzymatic activities were deficient (13). In this study, we observed the same type of dual deficiency in human CHS PMN, and were able to show by Western blotting for elastase and cathepsin $G$ that the enzymatic deficiency paralleled a deficiency of the respective immunoreactive proteins. Although we did not detect aberrant forms of elastase or cathepsin $\mathrm{G}$, such altered proteins could be unstable, present in very small amounts, or nonreactive with our antisera.

The azurophil granule proteins myeloperoxidase and betaglucuronidase have been reported to be normal (14) or mildly diminished (15) in CHS neutrophils, and lysozyme (muramidase activity) was also normal (14). The finding of normal acid-extractable protein content and preserved defensin content in CHS neutrophils confirms the relative selectivity of the elastase and cathepsin $\mathrm{G}$ defects. The recent measurements of normal elastase and cathepsin $G$ content in the bone marrow of beige mice (16) suggest that CHS may be a disorder of regulation of protein synthesis, protein processing, or granule assembly rather than a primary lesion in elastase and cathepsin $G$ genes.

$S G D$. Although the SGD neutrophils were reported to contain normal amounts of the azurophil granule proteins, myeloperoxidase and beta-glucuronidase, and lysozyme (17), previous studies of SGD neutrophils also contained indications of an azurophil granule defect. On sucrose or Percoll density gradients the azurophil granules sedimented as a single band of lighter density rather than the usual two bands (17, 18). The denser azurophil granules are ordinarily especially rich in defensins (19), which constitute almost half their total protein. Our observation that defensins are deficient in the PMN of these patients thus may explain the anomalous sedimentation pattern of their granulès. Future studies should clarify whether the PMN of SGD patients lack the morphologically distinct defensin-rich subpopulation of azurophil granules.

During normal maturation of azurophil granules, vicinal glycol groups in the granule matrix become masked so that they no longer stain with periodate-thiocarbohydrazide-silver proteinate stain (20). In SGD neutrophil's azurophil granules, this masking does not take place (20), consistent with the present demonstration that a triad of major azurophil granule proteins is missing in these PMN.

CHS and SGD: disorders of microbicidal/cytotoxic effector proteins of neutrophils. The azurophil granules of PMN are thought to function as specialized lysosomes containing proteins with digestive, microbicidal, and cytotoxic properties (21, 22). During phagocytosis azurophil granules fuse to phagosomes, release their contents onto the ingested target (23), and are thought to contribute to its destruction. Potential microbicidal effectors include several azurophil granule proteins with known antimicrobial activity in vitro: lysozyme, cathepsin G, bactericidal/permeability-increasing protein, CAP 37, defensins, and to a lesser extent, elastase (reviewed in references 24 and 25). Cathepsin G (26), elastase (27), and defensins (28) are also cytotoxic to certain mammalian cells and could contribute to tissue injury in vivo. In this report, we described two conditions in which there is a severe deficiency of either defensins (in SGD), or elastase and cathepsin G (CHS). In both of these conditions there is a previously unexplained defect in postphagocytic killing of bacteria $(17,29-32)$ despite a generally normal oxidative burst $(17,30,31,33)$. The profound deficiency of microbicidal/cytotoxic proteins in these disorders may contribute to the observed microbicidal defect in vitro and to the frequent bacterial infections characteristic of both conditions. Further studies of the ability of these defective neutrophils to kill various microbes and injure tissues may help clarify the role of elastase, cathepsin G, and defensins in these processes.

\section{Acknowledgments}

We thank Ms. Laura Mayo for obtaining the PMN of one of the patients with SGD, and Erika Valore for her capable technical assistance.

This work was sponsored in part by Public Health Service grants HL-35640 and AI-21931 to Dr. Ganz, AI-22838 to Dr. Lehrer, and AI-20065 and HL-31963 to Dr. Boxer from the National Institutes of Health.

\section{References}

1. White, C. J., and J. I. Gallin. 1986. Phagocyte defects. Clin. Immunol. Immunopathol. 40:50-61.

2. Parry, M. F., R. K. Root, J. A. Metcalf, K. K. Delaney, L. S. Kaplow, and W. J. Richar. 1981. Myeloperoxidase deficiency. Prevalence and clinical significance. Ann. Intern. Med. 95:293-301.

3. Gallin, J. I. 1985. Neutrophil specific granule deficiency. Annu. Rev. Med. 36:263-274.

4. Blume, R. S., and S. M. Wolff. 1972. The Chediak-Higashi syndrome: studies in four patients and a review of the literature. Medicine (Baltimore). 51:247-280.

5. Metcalf, J. A., J. I. Gallin, W. M. Nauseef, and R. K. Root. 1986. Laboratory Manual of Neutrophil Function. Raven Press, New York. 1-5.

6. Ganz, T., M. E. Selsted, D. Szklarek, S. S. L. Harwig, K. Daher, D. F. Bainton, and R. I. Lehrer. 1985. Defensins. Natural antibiotics of human neutrophils. J. Clin. Invest. 76:1427-1435.

7. Reisfeld, R. A., U. J. Lewis, and D. E. Williams. 1962. Disk electrophoresis of basic proteins and peptides on polyacrylamide gels. Nature (Lond.). 195:281-283.

8. Nakajima, K., J. C. Powers, B. M. Ashe, and M. Zimmerman. 1979. Mapping the extended substrate binding site of cathepsin $G$ and human leukocyte elastase. J. Biol. Chem. 254:4027-4032.

9. Ganz, T. 1987. Extracellular release of antimicrobial defensins by human polymorphonuclear leukocytes. Infect. Immun. 55:568571.

10. Smith, P. K., R. I. Krohn, G. T. Hermanson, A. K. Mallia, F. H. Gartner, M. D. Provenzano, E. K. Fujimoto, N. M. Goeke, B. J. Olson, and D. C. Klenk. 1985. Measurement of protein using bicinchoninic acid. Anal. Biochem. 150:76-85.

11. West, B. C. 1986. Chediak-Higashi Syndrome neutrophils are characterized by the absence of both normal azurophilic granules. Am. J. Pathol. 122:177-189.

12. Vassali, J. D., A. Piperno-Granelli, C. Griscelli, and E. Reich. 1978. Specific protease deficiency in polymorphonuclear leukocytes of Chediak-Higashi syndrome and beige mice. J. Exp. Med. 149:12851290.

13. Takeuchi, K., H. Wood, and R. T. Swank. 1986. Lysosomal elastase and cathepsin $\mathrm{G}$ in beige mice. Neutrophils of beige (ChediakHigashi) mice selectively lack lysosomal elastase and cathepsin G. $J$. Exp. Med. 163:665-677.

14. Stossel, T. P., R. K. Root, and M. Vaughan. 1972. Phagocytosis in chronic granulomatous disease and the Chediak-Higashi syndrome. N. Engl. J. Med. 286:120-123. 
15. Kimball, H. R., G. H. Ford, and S. M. Wolff. 1975. Lysosomal enzymes in normal and Chediak-Higashi blood leukocytes. J. Lab. Clin. Med. 86:616-630.

16. Takeuchi, K., M. P. McGarry, and R. T. Swank. 1987. Beige (Chediak-Higashi) mice express significant neutrophil elastase activity in bone marrow neutrophils. Fed. Proc. 46:985. (Abstr.)

17. Gallin, J. I., M. P. Fletcher, B. E. Seligmann, S. Hoffstein, K. Cehrs, and N. Mounessa. 1982. Human neutrophil-specific granule deficiency: a model to assess the role of neutrophil-specific granules in the evolution of the inflammatory response. Blood. 59:1317-1329.

18. Borregaard, N., L. A. Boxer, J. E. Smolen, and A. I. Tauber. 1985. Anomalous granule distribution in a patient with lactoferrin deficiency: pertinence to the respiratory burst. Am. J. Hematol. 18:255-260.

19. Rice, W. G., T. Ganz, J. M. Kinkade, Jr., M. E. Selsted, R. I. Lehrer, and R. T. Parmley. 1987. Defensin-rich dense granules of human neutrophils. Blood. 70:757-765.

20. Parmley, R. T., D. Y. Tzeng, R. L. Baehner, and L. A. Boxer. 1983. Abnormal distribution of complex carbohydrates in neutrophils of a patient with lactoferrin deficiency. Blood. 62:538-548.

21. Bretz, U., and M. Baggiolini. 1974. Biochemical and morphological characterization of azurophil and specific granules of human neutrophilic polymorphonuclear leukocytes. J. Cell Biol. 63:251-269.

22. Rest, R. F., M. H. Cooney, and J. K. Spitznagel. 1978. Bactericidal activity of specific and azurophil granules from human neutrophils: studies with outer-membrane mutants of Salmonella typhimurium LT-2. Infect. Immun. 19:131-137.

23. Zucker-Franklin, D., and J. G. Hirsch. 1964. Electron microscopic studies of the degranulation of rabbit peritoneal leukocyte during phagocytosis. J. Exp. Med. 120:569-576.

24. Ganz, T., M. E. Selsted, and R. I. Lehrer. 1986. Antimicrobial activity of phagocyte granule proteins. Semin. Respir. Infect. 1:107117.

25. Spitznagel, J. K. 1984. Nonoxidative antimicrobial reactions of leukocytes. Contemp. Top. Immunobiol. 14:283-343.

26. Clark, R. A., I. Olsson, and S. J. Klebanoff. 1976. Cytotoxicity for tumor cells of cationic proteins from human neutrophil granules. $J$. Cell Biol. 70:719-723.

27. Smedly, L. A., M. G. Tonnesen, R. A. Sandhaus, C. Haslett, L. A. Guthrie, R. B. Johnston, Jr., P. M. Henson, and G. S. Worthen. 1986. Neutrophil-mediated injury to endothelial cells. Enhancement by endotoxin and essential role of neutrophil elastase. J. Clin. Invest. 77:1233-1243.

28. Lichtenstein, A., T. Ganz, M. E. Selsted, and R. I. Lehrer. 1986. In vitro tumor cell cytolysis mediated by peptide defensins of human and rabbit granulocytes. Blood. 69:1407-1410.

29. Strauss, R. G., K. E. Bove, J. F. Jones, A. M. Mauer, and V. A. Fulginiti. 1974. An anomaly of neutrophil morphology with impaired function. N. Engl. J. Med. 290:478-484.

30. Ambruso, D. R., M. Sasada, H. Nishiyama, A. Kubo, A. Komiyama, and R. H. Allen. 1984. Defective bactericidal activity and absence of specific granules in neutrophils from a patient with recurrent bacterial infections. J. Clin. Immunol. 4:23-29.

31. Root, R. K., A. S. Rosenthal, and D. J. Balestra. 1972. Abnormal bactericidal, metabolic, and lysosomal functions of ChediakHigashi syndrome leukocytes. J. Clin. Invest. 51:649-665.

32. Clawson, C. C., J. E. Repine, and J. G. White. 1979. The Chediak-Higashi syndrome. Quantitation of a deficiency in maximal bactericidal capacity. Am. J. Pathol. 94:539-547.

33. Boxer, L. A., T. D. Coates, R. A. Haak, J. B. Wolach, S. Hoffstein, and R. L. Baehner. 1982. Lactoferrin deficiency associated with altered granulocyte function. N. Engl. J. Med. 307:404-410. 